\title{
A Teoria da Primeira Venda e os livros digitais
}

\section{Liliana Giusti Serra}

\begin{abstract}
Doutoranda em Ciência da Informação pela Universidade Estadual Paulista Julio de Mesquita Filho (UNESP). Mestre em Ciência da Informação pela Universidade de São Paulo, na Escola de Comunicações e Artes - ECA/USP. Especialista em Gerência de Sistemas pela Fundação Escola de Sociologia e Política de São Paulo (FaBCI/FESPSP)Profissional da informação da Prima (SophiA Biblioteca)
\end{abstract}

\section{José Eduardo Santarem Segundo}

\begin{abstract}
Doutor e Mestre em Ciência da Informação pela Universidade Estadual Paulista Júlio de Mesquita Filho-UNESP-Marília/SP. Docente e coordenador do Curso de Graduação em Ciências da Informação e da Documentação e Biblioteconomia, da Faculdade de Filosofia, Ciências e Letras de Ribeirão Preto, da Universidade de São Paulo (USP). Docente do Programa de Pós-Graduação em Ciência da Informação da UNESP/Marília na linha de Informação e Tecnologia
\end{abstract}

http://dx.doi.org/10.1590/1981-5344/2698

Este artigo analisa questões relacionadas à propriedade do livro digital em comparação com o impresso, abordando a distinção entre aquisição e licenciamento. A Teoria da Primeira Venda é aplicada a objetos físicos e discorre que o adquirente de um livro (o leitor ou a biblioteca) é proprietário do item e pode utiliza-lo livremente, podendo realizar empréstimos, revender, doar ou descartar, sem necessidade de pagamentos de direitos autorais ou recolhimento de taxas. Com os livros digitais a aplicação da teoria tem sido questionada, partindo da premissa que a obra é um software e não um objeto, portanto, não aplicável a estes recursos informacionais. 0 
método de pesquisa empregado é a pesquisa bibliográfica, com analise de referencial teórico coletado no período de 2005 a 2015 em revistas, livros, trabalhos de eventos e sítios da Web. A pesquisa é centrada em literatura estrangeira, com a abordagem de instituições como a European Bureau of Library, Information and Documentation Associations (EBLIDA), a American Library Association (ALA) e a International Federation of Library Associations (IFLA), e análise sobre a realidade brasileira. O estudo visa orientar sobre as alterações promovidas na biblioteca em relação ao licenciamento de conteúdo digital.

Palavras-chave: Teoria da primeira venda. Livros digitais. Licenciamento de conteúdo.

\section{The First Sale Doctrine and the digital books}

This article discusses the issues related to digital books property compared to printed books, addressing the distinction between acquisitions and licensing. The First Sale Doctrine is applied to physical objects and says that a book purchaser is the owner of the item and can use it freely, making loans, reselling, donating, or discarding without the need for payments of the copyrighted work. With digital books the application of the doctrine has been questioned, on the premise that the work is a software and not an object, and therefore not applicable to the First Sale Doctrine. This article uses the method of bibliographic research, with theoretical analysis collected from 2005 to 2015 in magazines, books, conference papers and Web sites. The research focused on foreign literature, including the opinion of institutions such as the European Bureau of Library, Information and Documentation Associations (EBLIDA), the American Library Association (ALA) and the International Federation of Library Associations (IFLA), plus analysis of the situation in Brazil. This article aims to guide librarians on the changes observed in the libraries related to digital content licensing under the aspect of the use of the media and availability of services contracted for the patrons.

Key-words: First sale doctrine; E-books; Digital content licensing 


\section{Introdução}

Os livros digitais são uma opção de recursos de informação aos acervos das bibliotecas e sua ampliação vem ocorrendo de forma gradativa, a partir do momento em que o mercado editorial expande a oferta de títulos. Com o aumento das obras disponíveis e das possibilidades de sua inclusão nas coleções, as bibliotecas observam transformações no processo de aquisição dos livros digitais em comparação com as obras impressas. Apesar de estarem habituadas com a aquisição de conteúdo eletrônico como assinaturas de periódicos ou bases de dados, são observadas diferenças na realização de licenciamento dos livros digitais, suscitando muitas dúvidas.

Se com os livros impressos o processo de compra é realizado com a seleção dos títulos desejados, pagamento, recebimento dos exemplares, processamento técnico e disponibilização aos usuários, com os livros digitais esta ordem não é seguida e, dependendo da modalidade de contratação realizada, o usuário tem acesso ao conteúdo sem que ocorra - licenciamento ou seleção por parte do bibliotecário, mas a partir de acessos realizados pelo usuário diretamente no catálogo ou na plataforma do fornecedor.

Outra questão que vem causando dúvidas está relacionada com a propriedade do livro digital. Enquanto a obra impressa pertence à biblioteca, muitas vezes recebendo numeração de tombo e patrimônio, com os livros digitais ocorre o licenciamento do conteúdo, porém sem transferência da propriedade do material ao licenciante. Na realidade, ao realizar a compra de um livro impresso a biblioteca tem a posse do objeto físico livro, em papel, e pode dispor deste objeto como bem entender, como, por exemplo, realizando empréstimos. Esta é a ideia base da Teoria da Primeira Venda. Com os livros digitais, por não serem comercializados em exemplares, não está presente a materialidade do objeto, com a entendimento de propriedade sendo abalado, a partir do momento que nenhum suporte físico está envolvido, podendo impedir, inclusive, a realização de empréstimos.

Este artigo discute as transformações do processo de aquisição em relação aos livros digitais e a ruptura da Teoria da Primeira Venda, que acarreta em comprometimento do uso que as bibliotecas podem fazer dos títulos digitais licenciados presentes em seus acervos.

\section{Contextualização}

Enquanto com livros impressos as opções de negociação das bibliotecas com os fornecedores estavam estabelecidas, principalmente nas figuras de editores e distribuidores, com os livros digitais o cenário ainda é de indefinição. Para licenciamento destes materiais existem, principalmente, três tipos de fornecedores para bibliotecas: editores, 
distribuidores e agregadores de conteúdo (POLANKA, 2011). Para Sheehan (2013, p. 66, tradução nossa) a biblioteca "compra livros, no formato eletrônico, mas o acesso a eles é mediado por uma terceira parte. Se esta terceira parte sai do negócio ou vende sua divisão de livros digitais, [a biblioteca] possui livros que potencialmente não consegue utilizar".

Os livros digitais licenciados apresentam complexidades inexistentes em relação aos impressos. Sua descoberta pode ocorrer no catálogo da biblioteca (Online Public Access Catalogue - OPAC) e/ou na plataforma do fornecedor. Independentemente do local da descoberta, a leitura será realizada, via de regra, na plataforma do fornecedor, oferecendo os serviços definidos pela terceira parte.

Nem sempre a biblioteca terá liberdade para definir os prazos de empréstimo e, em alguns casos, o acesso ao conteúdo poderá ser condicionado à conexão com a Internet, sem permitir a leitura desconectada (off-line), a realização de cópias ou impressão de trechos das obras.

Os fornecedores ainda apresentam relutância no fornecimento de livros digitais para bibliotecas. A preocupação centra-se na queda das vendas, com as bibliotecas realizando um licenciamento - que garantiria a condição de inúmeros acessos - ao invés de adquirir diversos exemplares (SHATZKIN, 2011 apud SHEEHAN, 2013). Também existe o receio da pirataria ou acesso desordenado. Para coibir o uso e distribuição não contratados, os editores aplicam ferramentas de Digital Rights Management - DRM ${ }^{2}$ ) nos livros, restringindo as possibilidades de acesso e, inclusive, podendo comprometer a leitura.

O DRM é um dos quatro elementos e parte intrínseca do livro digital. Assim como o dispositivo de leitura (equipamento, hardware), o formato do arquivo (que pode ser aberto ou proprietário) e a plataforma (software, responsável pela mediação da leitura), o DRM controla o uso que será feito do conteúdo (SERRA, 2015). Esta ferramenta é aplicada com o intuito de coibir cópias, distribuição ilegal ou uso não autorizado de material licenciado. Segundo Harte (2007, cap. 1, tradução nossa), "sistemas de DRM devem identificar e descrever a mídia, atribuir e identificar os direitos associados a ela e garantir que as solicitações venham de usuários autorizados". Segundo o autor, são aplicações cliente-servidor que recebem as solicitações e, através de codificação do conteúdo, permitem o acesso após validar a encriptação correta. Funcionam como um cadeado. Se o dispositivo ou o aplicativo não tiverem a chave para abrir este cadeado, o acesso não será permitido. Assim, quando combinado com o formato do arquivo, dispositivos compatíveis e uso de plataformas proprietárias, controlará o acesso ao conteúdo pelo leitor.

Fornecedores já praticaram embargo em lançamentos, impedindo que a biblioteca comprasse títulos digitais. Esta prática foi adotada por

\footnotetext{
${ }^{1}$ SHATZKIN, M. Interview by author. Phone call November 7, 2011 (informação verbal).

${ }^{2}$ Gestão de Direito Digital, tradução nossa.
} 
editores nos Estados Unidos garantindo, assim, que um lançamento teria uma venda expressiva antes de oferecer a versão digital da publicação à biblioteca. Outra prática adotada por fornecedores foi estipular preços muito altos, em alguns casos ultrapassando em 300\% o valor da obra impressa. Ocorreram também situações onde os editores se recusavam a vender para bibliotecas. Estas ações são decorrentes de receios de pirataria ou utilização diferente da contratada, que representariam perdas aos fornecedores. Outra precaução estava centrada no entendimento que os livros digitais estariam acessíveis nos catálogos das bibliotecas na Web e que qualquer pessoa poderia acessa-los, de forma gratuita. Isto representaria queda expressiva nas vendas do fornecedor (INTERNATIONAL FEDERATION OF LIBRARIES ASSOCIATIONS - IFLA, 2013). Este entendimento é equivocado, afinal os livros digitais licenciados são disponibilizados somente para os usuários com cadastro ativo na instituição, com acesso por meio de login e senha.

Contrário ao pensamento de que ao dispor de livros digitais nos catálogos acarretariam em quedas nas vendas dos fornecedores, Arévalo, Gómez Díaz e Cordón Garcia (2015, p. 207, tradução nossa) destacam resultados obtidos em pesquisa desenvolvida pelo Pew Research:

[...] bibliotecas são pontos muito importantes de comercialização e visibilidade dos livros, e que são precisamente os usuários das bibliotecas os leitores mais intensos, quem mais livros leem e que mais livros compram.

Este mesmo entendimento é alcançado pela pesquisa conduzida pela American Library Association e o OverDrive, expressivo agregador de conteúdo atuante nos Estados Unidos e Europa, em 2012. Esta pesquisa foi realizada com 75.000 participantes e $57 \%$ dos usuários relataram que a biblioteca pública foi o local de descoberta dos livros. Também pontua que se um livro digital está indisponível (emprestado para um usuário) na biblioteca, $53 \%$ dos participantes consideravam a possibilidade de compra-lo em uma livraria. Ou ainda, que 35,3\% dos entrevistados informaram que compraram livros (impressos ou digitais) após a realização de empréstimos nas bibliotecas (OVERDRIVE; AMERICAN LIBRARY ASSOCIATION, 2012). Pode-se acrescentar, ainda, que as bibliotecas são compradoras de livros digitais, além de serem canais para divulgação dos mesmos e ponto para descoberta de novos títulos e autores.

Segundo Geist (2012), o empréstimo de livros impressos não representava um problema às editoras devido a:

1) os exemplares são emprestados a um usuário por vez;

2) as bibliotecas atendem a comunidade próxima, exigindo que os usuários se desloquem até o prédio, localizem as obras desejadas, façam os empréstimos e, após o período definido, que retornem ao local para devolve-los; 
3) os riscos de pirataria eram menores, afinal copiar uma obra completa exige tempo e trabalho, além das punições existentes a quem viola os direitos de autor;

4) a biblioteca favorece a divulgação das obras dos editores, além de trabalhar com a preservação das mesmas.

Enquanto bibliotecas e editores trabalhavam com livros impressos, existia um equilíbrio, com os empréstimos não representando, de forma pungente, um descompasso entre ambos, até porque as bibliotecas formam boa parte de seus acervos por meio de aquisições. Com os livros digitais a situação foi alterada.

No cenário dos livros digitais as bibliotecas não compram exemplares, mas realizam contratos de licenciamento de conteúdo. Ao eliminar a materialidade do livro e constatar a inexistência de um objeto tangível nas transações comerciais de conteúdos digitais, o processo de aquisição deixa de ser inerente a um objeto físico e passa a ser um serviço, com sua comercialização sendo realizada por meio de contratos de licenciamento, em semelhança a softwares (MAIA, 2013), removendo o conceito da propriedade, mas outorgando uma licença de uso.

Editores e bibliotecas existem para prover acesso à informação, porém encontram-se em perspectivas opostas: editores ganham dinheiro ao vender acesso ao conteúdo que publicam, enquanto bibliotecas oferecem os conteúdos de forma franqueada a seus usuários (GEIST, 2012).

\section{Procedimentos metodológicos}

O artigo analisa a Teoria da Primeira Venda em relação aos livros digitais e suas implicações nas bibliotecas. A metodologia empregada consiste em estudo bibliográfico que recolhe, analisa e comenta a literatura identificada em artigos, livros, anais de eventos e demais materiais coletados, com recorte temporal de 2005 a 2016.

É analisado o amparo legal da Teoria da Primeira Venda na Europa, Estados Unidos e Brasil, incluindo as manifestações de associações de bibliotecários como a European Bureau of Library, Information and Documentation Associations (EBLIDA), a American Library Association (ALA) e a International Federation of Library Associations (IFLA).

\section{Aquisição x licenciamento}

Para Sheehan (2013) nos últimos vinte anos o entendimento de propriedade foi alterado, ocasionando desafios culturais. A partir do momento em que um produto era adquirido ele pertencia ao adquirente, criando um sentimento de posse dos objetos. A propriedade é parte da parcela do entendimento cultural dos livros. Com os livros digitais, este entendimento não é alcançado, principalmente pela necessidade de conhecimento tecnológico para finalizar a compra e realizar a leitura. 
Ao comprar um livro digital não existe o objeto tangível. Este produto deverá ser acessado por meio de dispositivos de leitura e mediados por plataformas. O adquirente não poderá armazenar os arquivos digitais em seus servidores, mas terá acesso aos mesmos de acordo com a forma com que foi feito o licenciamento. Este entendimento é dispensado a leitores e bibliotecas.

Caso a biblioteca opte por adquirir dispositivos de leitura e armazenar os livros digitais nestes equipamentos, ao substituir os aparelhos, os títulos licenciados podem ser dispostos em novos dispositivos, visto que a licença de uso não foi alterada, permitindo, em muitos casos, que o produto possa ser acessado por outros equipamentos identificados do licenciante.

Entretanto, o licenciamento de livros digitais ocorre de forma diferente para uso pessoal (leitores) e bibliotecas. Enquanto os leitores adquirem seus livros digitais essencialmente em livrarias virtuais, as bibliotecas realizam usualmente a contratação por meio de fornecedores específicos, como editores, agregadores de conteúdo ou distribuidores, mediante adoção de modelos de negócios.

As ferramentas utilizadas nas livrarias virtuais não são desenvolvidas com foco nas bibliotecas, visto que priorizam o mercado consumidor dos leitores. Mesmo que a biblioteca opte por adquirir livros digitais em livrarias virtuais e empreste os dispositivos de leitura onde o conteúdo foi armazenado, observará as restrições impostas por esta forma de licenciamento, realizando o empréstimo de um dispositivo que possui diversos livros digitais, favorecendo um único usuário em detrimento da comunidade, visto que todos os títulos presentes no dispositivo estarão acessíveis somente para aquele que realizou o empréstimo. A circulação de dispositivos é realizada por algumas bibliotecas e assegura a manutenção do processo de compra, transformando o livro digital em um objeto tangível, transmitindo o entendimento que o sentimento de posse foi preservado.

Para Maia (2013), a relação de compra e venda dos livros digitais, diferentemente dos livros impressos, é regida pela Lei no 9.609, de 1998, que em seu Artigo 9 enumera que "o uso de programa de computador no País será objeto de contrato de licença". O Artigo $2^{\circ}$ desta lei define que "o regime de proteção à propriedade intelectual de programa de computador é o conferido às obras literárias pela legislação de direitos autorais e conexos vigentes no País, observado o disposto nesta Lei" (BRASIL. Presidência da República, 1998a).

Os contratos de licenciamento de software são variados e aspectos de uso são detalhados de acordo com manifestação do desenvolvedor, situação observada em ferramentas abertas ou proprietárias. Em alguns casos, é comercializada a licença de forma perpétua, transferindo propriedade ao adquirente sem, contudo, permitir a locação, doação ou cessão desta para terceiras partes. Se não for firmado contrato de manutenção que garanta a atualização e eventuais ações corretivas no sistema, o vínculo com o contratante é cessado, contudo sem que ocorra a suspensão da utilização do software. O contratante possui propriedade 
da licença e pode utilizar o sistema, mesmo que não seja atualizado. Em aplicações Web se observa a prática de não comercialização da licença, facultando o uso do software mediante contratação periódica e, caso não ocorra a renovação do contrato, é encerado o acesso, sem manutenção da solução contratada. Da mesma forma que ocorre com softwares e, sendo o livro digital identificado desta forma, é esperado que permissões e restrições sejam estabelecidas pelos fornecedores, resultando em contratos de licenciamento variados, que exigem atenção e apuro por parte do bibliotecário.

Sob o ponto de vista da biblioteca, as mudanças no processo de aquisição decorrentes dos livros digitais são significativas porque a relação fornecedor-biblioteca não está mais centrada na aquisição e recebimento dos títulos, mas na contratação de fornecedores que realizarão uma prestação de serviço, disponibilizando o acesso aos títulos dentro do período contratado.

De acordo com Arévalo, Gómez Díaz e Cordón Garcia (2015) o formato digital levou a indústria editorial a apoiar-se nos modelos praticados pelo mercado de softwares e de comercialização de bases de dados, não se apoiando mais na venda de exemplares dos títulos publicados. Estes modelos digitais são estruturados com base em autorizações para visualização temporária do conteúdo (podendo ocorrer por meio de streaming) ou através da realização de downloads dos conteúdos, ocorrendo um pagamento pelo uso, que pode ser interpretado como um aluguel ou assinatura de serviço, mas que não compreende a comercialização dos direitos autorais ou patrimoniais. As obras "digitais que se comercializam através de redes não são vendidas, a não ser por um objeto de licenças de usuários finais que impedem uma posterior revenda ou transmissão a terceiros" (ARÉVALO; GOMÉZ DIAS; CORDÓN GARCIA, 2015, p. 229, tradução nossa). Este entendimento provoca transformações no processo de aquisição e propriedade de obras presentes em acervos, afetando diretamente as bibliotecas. Podemos dizer que os livros digitais são analisados e comercializados como se fossem softwares e não como produtos. Evidentemente este tema pode acarretar interpretações dúbias, com a opção de propriedade da licença ou permissão de uso da mesma. A literatura analisada interpreta que o livro digital é licenciado como software, porém este aspecto suscita novos estudos e análise de possibilidades de aplicação, principalmente perante a legislação brasileira.

Segundo Rocha (2007), o proprietário ou desenvolvedor de um software é o detentor dos direitos autorais e pode cede-lo a terceiras partes - identificados como contratantes - por tempo indeterminado e sem exclusividade, permitindo, inclusive, que o programa seja instalado em servidores sob gestão e guarda externa ou pelos próprios contratantes. Por outro lado, o contratante passa a ter o direito de uso do software, porém não sua propriedade, o que impede a transferência, empréstimo, doação, revenda, arrendamento, alienação, sublocação ou ainda a opção de dar o sistema como objeto em garantia em transações comerciais. 
Saavedra (1998 ${ }^{3}$ apud MAIA, 2013) discorre que a cessão de uso e os contratos de licenciamento são protegidos pelo direito de autor, protegendo o desenvolvedor do software e não necessariamente quem o comercializa. Os sistemas são comercializados mediante contratos de licenciamento realizados entre uma empresa (desenvolvedora ou sua representante) e a instituição ou pessoa que utilizará o software. Estes contratos expressam os direitos do autor e limitam a liberdade do adquirente, podendo conter cláusulas que, por exemplo, proíbam ou controlem o uso simultâneo, possuam restrições de instalação, reprodução, cópia ou alteração de código fonte, limitem os empréstimos, locação ou demais transações comerciais relacionadas ao software licenciado.

Para a biblioteca, não ter a propriedade dos livros digitais acarreta em complexidades, com a construção da coleção prejudicada pela não determinação da permanência de um título no acervo ou o uso que pode ser feito dele. Assim, caso se confirme o entendimento que o livro digital é um software e não um produto, empréstimos podem ser vedados, com a biblioteca impedida de prestar este serviço.

\section{A Teoria da Primeira Venda}

A Teoria da Primeira Venda (first sale doctrine) é aplicada a objetos físicos. Ela sustenta que quando uma obra é adquirida, sua propriedade é transferida ao adquirente, que pode fazer o uso que desejar deste objeto. Esta característica permite que as bibliotecas realizem empréstimos, doações, permutas, vendas ou descartes, afinal aquele exemplar é de sua propriedade e ela pode usá-lo de acordo com seus interesses. Esta propriedade, entretanto, não transfere os direitos autorais da referida obra ao adquirente, não sendo permitida a cópia do conteúdo sem autorização do autor ou seu representante legal. Entretanto, caso a biblioteca deseje realizar uma cópia ou transformação do conteúdo original, deverá consultar o autor ou editor e, em caso de consentimento, recolher o direito autoral definido para esta atividade.

A teoria, portanto, define que ao adquirir uma publicação, a biblioteca é proprietária do exemplar, visto que possui os direitos de propriedade do objeto. Por outro lado, não pode alterar o texto ou reproduzir o conteúdo sem autorização expressa dos detentores, uma vez que a propriedade do objeto não the confere direitos autorais (MAIA, 2013; SHEEHAN, 2013). A Teoria da Primeira Venda também é estendida aos leitores ao permitir que compartilhem seus livros com familiares e amigos, vendam, descartem, doem etc.

A Figura 1 representa a Teoria da Primeira Venda que, ao permitir que um leitor ou biblioteca, após adquirir uma publicação produzida por um autor e comercializada por um editor/vendedor, possa revendê-la, empresta-la ou descarta-la.

Figura 1 - Teoria da Primeira Venda

\footnotetext{
${ }^{3}$ SAAVEDRA, R. A proteção jurídica do software e a Internet. Lisboa: Don Quixote, 1998.
} 


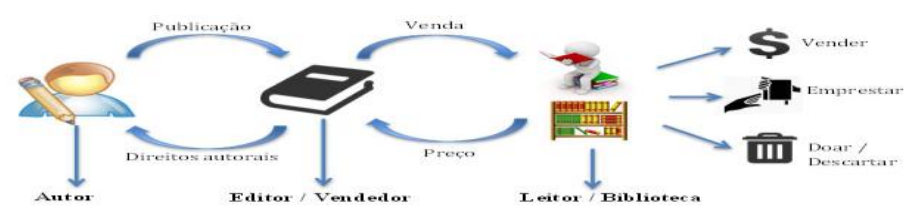

Fonte: Elaborado pelos autores com base em HARTE (2007).

Já com os livros digitais, construídos com ferramentas de DRM, ocorrem restrições de acesso, além da impossibilidade de revenda ou realização de empréstimos ou doações (MCGUIRE; O'LEARY, 2012). O Digital Millennium Copyright Act (DMCA), de 1998, permite aos editores o uso de ferramentas para coibir a pirataria, comprometendo o alcance da Teoria da Primeira Venda (GEIST, 2012).

A teoria é definida pela Lei de Copyright dos Estados Unidos em seu parágrafo 109 que discorre:

A Teoria da Primeira Venda, codificada na 17 U.S.C §109, prevê que um indivíduo que adquiriu uma cópia de obra protegida por direito autoral tem o direito de vender, expor ou descartar esta cópia em particular, independente do interesse do proprietário do direito (THE UNITED..., 2011, tradução nossa).

A primeira Lei de Direitos Autorais dos Estados Unidos, datada de 1790, atestava que produções intelectuais somente poderiam ser comercializados pelos detentores dos direitos autorais pelo prazo de quatorze anos. Esta situação foi colocada em xeque quando um grupo editor incluiu nota em seus livros atestando que os mesmos eram protegidos e que não poderiam ser revendidos por valor menor praticado por eles. Quando um vendedor se recusou a seguir esta orientação, 0 mesmo foi processado. O caso Bobbs-Merril vs. Strauss, de 1908, questionava que apenas os editores poderiam ganhar com a venda dos livros, restringindo vendas e lucros futuros. Como não existiam orientações contratuais que controlavam revendas subsequentes de uma obra, a Subcomissão de Direitos Autorais do Tribunal de Justiça chegou ao entendimento que autores e seus representantes legais não teriam como controlar a revenda de seus trabalhos, alterando a legislação em 1909. Enquanto os editores enxergaram esta mudança com desconfiança e descrédito, as bibliotecas identificaram como liberdade para circulação do pensamento. Nova alteração na legislação ocorreu em 1976, removendo a autorização exclusiva de possuidores de direitos autorais em realizar a venda, estendendo esta possibilidade aos possuidores dos exemplares, além de incluir, neste conjunto, o empréstimo ou aluguel, consolidando a teoria no artigo 109 da Lei de Direitos Autorais Norte Americana (GEIST, 2012).

As bibliotecas respondem às exigências da Teoria da Primeira Venda, tendo o direito de emprestar os materiais sem a necessidade de solicitar permissão de autores ou editores sempre que um usuário requisitar a consulta dos mesmos, sem necessidade da realização de novas transações financeiras ou recolhimento de taxas de direitos 
autorais, ou ainda de anuência de autores ou editores (SHEEHAN, 2013; WOODWARD, 2013).

Para Geist (2012), a Teoria da Primeira Venda contribui com as bibliotecas devido a três fatores:

1) proporciona autonomia às bibliotecas para emprestarem obras pertencentes aos acervos e protegidas por direitos autorais, dispensando-as de solicitar autorizações para empréstimo aos seus representantes legais;

2) permite às bibliotecas construírem suas coleções e emprestar seus exemplares inúmeras vezes, tornando-as economicamente possíveis, sem a necessidade de investimentos repetidos para utilizar as obras presentes em seus acervos, ou seja, após um investimento inicial, uma publicação pode ser utilizada diversas vezes, sem necessidade de realização de novos aportes financeiros. A teoria também permite às bibliotecas o empréstimo entre bibliotecas, evitando a aquisição de obras com baixa solicitação por parte dos usuários, sem exigir a compra da mesma;

3) permite a comercialização de obras usadas, com a biblioteca podendo receber ou fazer doações, trocar ou revender suas obras ou adquirir títulos de seu interesse a preços competitivos, em sebos.

Segundo a International Federation of Library Associations (IFLA, 2013), as bibliotecas ficam enfraquecidas na medida em que a Teoria da Primeira Venda é alterada, com seu papel social e cultural de acesso às informações prejudicado. Devido a este risco, a instituição aponta a necessidade de discussões e acordos com os fornecedores sobre aquisição de conteúdo digital, na forma de garantir a habilidade de escolher e disponibilizar obras, com acesso gratuito, assegurando a manutenção da missão das bibliotecas, estendendo a Teoria da Primeira Venda ao ambiente digital.

A legislação brasileira orienta no Artigo 37 da Lei do Direito Autoral (Lei 9.610, de 1998): "Art. 37: A aquisição do original de uma obra, ou de exemplar, não confere ao adquirente qualquer dos direitos patrimoniais do autor, salvo convenção em contrário entre as partes e os casos previstos nesta Lei" (BRASIL. Presidência da República, 1998b). As bibliotecas e sebos no Brasil, entretanto, não possuem legislação específica (COSTA, 2015), e não discorrem sobre a Teoria da Primeira Venda de forma explícita.

A Lei de Direitos Autorais deixa claro que a aquisição de um livro não representa propriedade dos direitos autorais do mesmo. Segundo a Teoria da Primeira Venda, os direitos do adquirente são reservados ao comprador e não ao portador (MAIA, 2013). Levando este entendimento para o cenário das bibliotecas, a instituição que comprou um exemplar pode empresta-lo a seus usuários. Um usuário, entretanto, não pode 
repassar este exemplar para outra pessoa, visto que não é o proprietário do objeto.

$\mathrm{Na}$ lei de direitos autorais brasileira também é abordada a utilização de bases de dados, que podem ser interpretadas como obras similares aos livros digitais por serem registros consultados por meio de plataforma proprietária, mediante contratação. Em seu Art. 87, a Lei no. 9.610/1998 atesta que:

Art. 87 - O titular do direito patrimonial sobre uma base de dados terá o direito exclusivo, a respeito da forma de expressão da estrutura da referida base, de autorizar ou proibir:

I - sua reprodução total ou parcial, por qualquer meio ou processo;

II - sua tradução, adaptação, reordenação ou qualquer outra modificação;

III - sua distribuição do original ou cópias da base de dados ou a sua comunicação com o público;

IV - a reprodução, distribuição ou comunicação ao público dos resultados das operações mencionadas no inciso II deste artigo (BRASIL. Presidência da República, 1998b).

Apesar da legislação brasileira sobre direitos autorais estar em análise para atualização em relação às questões digitais - movimento que ocorre em todo o mundo - este ponto reforça a interpretação de realizar a comercialização de livros digitais como software ou, neste caso, bases de dados, podendo ocorrer restrição de uso do conteúdo por terceiros, no caso, os usuários.

De acordo com Rao (2005) a Teoria da Primeira Venda está presente em bibliotecas há séculos e permite o empréstimo de forma legalizada. No âmbito dos livros digitais, porém, o direito de realizar empréstimos é questionado, com o licenciamento sobrepondo-se à propriedade, inibindo a realização de circulações.

Maia (2013) e Woodward (2013) enfatizam que os livros digitais têm sua comercialização realizada em semelhança aos programas de computador, e não aderente à Teoria da Primeira Venda, com restrições de doação, revenda ou empréstimo por parte do comprador. O mesmo entendimento é obtido pelo European Bureau of Library, Information and Documentation Associations (2013), com a Corte de Justiça da Europa definindo que a aquisição de livros digitais se assemelha ao licenciamento de software. Portanto, a Teoria da Primeira Venda não é aplicável ao livro digital devido a presença de ferramentas tecnológicas que impedem a revenda e a realização de empréstimos e doações; além de ser considerado um software (serviço) e não um objeto (produto).

A Teoria da Primeira Venda tornou-se complexa com o licenciamento dos livros digitais conforme:

Ao rever uma licença é importante que os usos que você precisa fazer da versão digital sejam permitidos, quer explicitamente através de uma cláusula no contrato que discorre a forma como o conteúdo pode ser usado, ou implicitamente, preservando sua 
capacidade de exercer os seus direitos sob a lei de direitos autorais (ALBITZ; BRENNAM, 2012, p. 79, tradução nossa).

De acordo com Geist (2012), as bibliotecas tentaram estender a Teoria da Primeira Venda ao ambiente digital, evocando que, após o uso de conteúdo digital licenciado, os arquivos seriam apagados dos dispositivos de usuários, não permitindo a distribuição não controlada das obras licenciadas. Porém, fornecedores não se mostram favoráveis a esta possibilidade, demonstrando interesse em propor modelos de negócios com pagamentos ocorrendo de acordo com o uso da mídia (pay-perview), eliminando a propriedade e o uso irrestrito de uma obra digital. Como as transações comerciais de recursos digitais ainda não estão estabelecidas, com modelos de negócios sendo testados, os congressistas norte-americanos posicionaram-se no sentido de aguardar a acomodação do mercado antes de manifestar-se sobre a permanência ou eliminação da Teoria da Primeira Venda em relação aos objetos digitais.

Segundo Woodward (2013), a American Library Association, a Association for College and Research Libraries, a Association of Research Libraries, o Electronic Frontier Foundation, o Consumer Federation of America e o U.S. Public Interest Research Group and Public Knowledge criaram uma coalisão para apoiar a Teoria da Primeira Venda:

[A coalisão] argumenta que a Teoria da Primeira Venda promove o acesso ao conhecimento, preservação da cultura e resistência à censura. A comunidade da biblioteca compreende que os negócios e o trabalho individual devem ser recompensados e a capacidade de fazer legalmente cópias ilimitadas de livros digitais, arquivos sonoros ou programas de computador poderiam remover o incentivo da criação e condução dos negócios. Entretanto, delegar aos editores digitais a definição de todas as regras e impor restrições de acordo com a vontade deles não é uma solução igualmente satisfatória (WOODWARD, 2013, p. 16, tradução nossa).

A European Bureau of Library, Information and Documentation Associations é uma organização independente europeia que discute a utilização de livros digitais em relação a questões de direitos autorais, licenciamento, cultura e educação, além do livre acesso à informação na era digital e o papel de arquivos e bibliotecas. A instituição desenvolve estudos e ações de trabalho promovendo a divulgação de princípios que norteiam a atividade bibliotecária em relação ao uso de conteúdos digitais em bibliotecas. Nestes princípios destacam-se:

a) aquisição: a biblioteca tem o direito de poder adquirir todos os títulos de livros digitais disponíveis, a partir do momento de seu lançamento e em formatos interoperáveis;

b) acesso: possui o direito de disponibilizar os livros digitais aos seus usuários por período definido pela instituição, assim como garantir o acesso simultâneo a usuários identificados; 
c) download: garante a realização do download no espaço da biblioteca ou por acesso remoto autenticado;

d) negociação: com fornecedores, buscando alternativas aceitáveis para bibliotecas e editores;

e) serviços: as licenças dos livros digitais devem contemplar o empréstimo entre bibliotecas;

f) acesso contínuo e preservação de longo prazo: opção de armazenar 0 arquivo digital permanentemente, podendo transferi-lo para outras plataformas, de acordo com mudanças tecnológicas. Bibliotecas devem receber todas as versões existentes caso a publicação adquirida não esteja mais disponível comercialmente. Os termos contratuais da licença não devem ultrapassar as disposições legais relacionados à entrada da obra em domínio público;

g) disponibilidade de metadados: devem ser oferecidos pelos fornecedores para que a biblioteca os inclua em seus catálogos bibliográficos;

h) preços: os valores dos livros digitais não devem ultrapassar os preços estabelecidos em suas versões impressas e podem sofrer decréscimo de acordo com a data da publicação;

i) privacidade: os dados pessoais dos usuários devem ser processados e armazenados exclusivamente pelas bibliotecas, não sendo aceitável o acesso a terceiros como editores ou fornecedores, a não ser que consentido.

De acordo com o European Bureau of Library, Information and Documentation Associations (2012) as bibliotecas asseguram o livre acesso aos conteúdos, à informação e à cultura a todos os cidadãos europeus. Garantem o direito de distribuição após a primeira venda, ou seja, ao comprar obras publicadas (livros), os exemplares podem ser emprestados aos usuários sem necessidade de novo investimento financeiro, e sem interferir nos direitos de autor. As bibliotecas têm autonomia para definir quais obras serão adquiridas, de acordo com sua política de aquisições, facultando sua utilização a seus usuários. Assim, para a European Bureau of Library, Information and Documentation Associations, as bibliotecas são resguardadas pela Teoria da Primeira Venda, pois possuem o direito de distribuição dos livros após sua aquisição.

A International Federation of Library Associations, em seus Princípios do Empréstimo Digital, atualizado em agosto de 2013, apresenta forte semelhança com os objetivos da European Bureau of Library, Information and Documentation Associations, ao definir que:

a) as bibliotecas têm o direito de licenciar qualquer livro digital, sem a ocorrência de embargos; 
b) os preços oferecidos às bibliotecas devem ser condizentes com o mercado. Os termos devem ser claros e os custos compatíveis com os orçamentos das instituições;

c) as licenças devem permitir cópias de parte dos conteúdos e para fins de preservação, realização de empréstimo entre bibliotecas, transformar a obra para que fique acessível a pessoas com deficiências físicas e poder remover restrições tecnológicas que dificultem o acesso;

d) fornecedores devem adotar plataformas neutras, desenvolvidas com padrões de acessibilidade, além de compatíveis com dispositivos e aplicações, garantindo a interoperabilidade entre dispositivos e plataformas;

e) definir estratégias para garantir a preservação de longo prazo dos livros digitais, evitando a perda de obras cujos fornecedores saírem do mercado ou perderem seus direitos de representação;

f) a privacidade dos usuários deve ser preservada, sem distribuição de informações pessoais ou hábitos de leitura para fornecedores.

Segundo o European Bureau of Library, Information and Documentation Associations (2012), o atual quadro jurídico afeta o cumprimento da missão das bibliotecas pelas restrições para empréstimo de livros digitais adquiridos. O mesmo entendimento é alcançado pela American Library Association (2014) ao manifestar que as bibliotecas são protegidas pelas Teorias da Primeira Venda (first sale) e do Uso Justo (fair use), garantindo a utilização de obras protegidas por direitos autorais com os propósitos de crítica, comentários, estudo ou pesquisa. A legislação norte-americana também garante às bibliotecas o direito de realizar reproduções de obras protegidas com fins de reposição ou preservação, ou ainda para garantir o acesso a usuários possuidores de deficiências físicas. Segundo a American Library Association (2015), a Teoria da Primeira Venda é "o que permite que as bibliotecas façam o que fazem: emprestem livros e materiais a nossos usuários, o público" (tradução nossa).

A ideia do licenciamento é aplicada a softwares, mas não a livros (SHEEHAN, 2013). Além das questões relacionadas à Teoria da Primeira Venda e do licenciamento versus a propriedade, os livros digitais também apresentam restrições territoriais. De acordo com Walters (2013) e Geist (2012), o cruzar de fronteiras pode afetar a disponibilidade dos livros digitais armazenados nos dispositivos de leitura, de acordo com o contrato de licenciamento definido. Caso um leitor cruze uma fronteira, seus livros digitais poderão ficar indisponíveis se o contrato de licenciamento não contemplar o país visitado. Isto decorre do fato que livros digitais são oferecidos para licenciamento através de contratos estabelecidos entre as editoras e países. Desta forma, uma publicação do Canadá pode ter sua 
comercialização restrita a este país, ou a possuidores de cartões de crédito aceitos nesta localidade.

O sentido de licenciamento em oposição à propriedade tornou-se evidente quando a Amazon removeu de sua loja e dos dispositivos dos leitores a cópia dos livros 1984 e A Revolução dos Bichos, de George Orwell, ao identificar que foram disponibilizados de forma ilegal para download. Com a constatação da loja virtual de que as cópias comercializadas não eram legais - após reclamação dos detentores dos direitos - além de remover os títulos da loja para impedir futuras comercializações, os retirou dos dispositivos dos leitores, realizando estorno dos valores pagos. Após este fato, ocorrido em 2009, a Amazon se comprometeu a não realizar a mesma ação, caso fossem identificados outros casos similares (STONE, 2009). Apesar do valor do licenciamento ter sido devolvido aos leitores, a remoção de cópias adquiridas legalmente dos dispositivos dos usuários por parte do fornecedor expos a fragilidade na manutenção dos livros digitais aos contratantes, reforçando a ideia de posse de permissão temporária de uso, mas não a propriedade do conteúdo, o que suscita temores de acesso e utilização de títulos licenciados em longo prazo, preocupações não somente centradas nesta situação, mas também sob os aspectos de preservação digital.

Segundo Konnikova (2012):

Um livro digital não é um livro físico. Este ponto pode parecer banal até você parar por um momento e pensar o quanto é simples, de certa forma, destruir um vestígio eletrônico ao invés de um físico (KONNIKOVA, 2012, tradução nossa).

Dentre as atividades desenvolvidas pelas bibliotecas, o Empréstimo Entre Bibliotecas (EEB) apresenta restrições, com as possibilidades de licenciamento inibidas. De acordo com Gee (2007), os modelos de licenciamento não suportam a aplicação de empréstimos entre bibliotecas. Isto ocorre porque a biblioteca responsável pelo licenciamento não pode oferecer o livro digital a uma outra biblioteca, exigindo que a segunda também realize o licenciamento do título em questão.

As bibliotecas realizam licenciamentos de livros digitais por meio da aplicação de modelo de negócio, que pode ser perene ou sem data para expirar (Aquisição Perpétua), ou transitório, como a Assinatura, Demand Driven Acquisition (DDA $)^{4}$, Short Term Loan (STL) ${ }^{5}$, Evidence Based Acquisition (EBA $)^{6}$, entre outras possibilidades (SERRA; SILVA, 2016). Entretanto, nas modalidades de licenciamento disponíveis para bibliotecas, a questão da propriedade não se apresenta estável, com a biblioteca contratando um serviço que permite acesso ao livro digital, mas não sua propriedade, fragilizando a manutenção dos acervos ou a preservação de títulos na coleção em longo prazo. Este caso é nítido nos modelos transitórios, porém também pode ocorrer na Aquisição perpétua, caso ocorram restrições do fornecedor para prover acesso às obras em

\footnotetext{
${ }^{4}$ Aquisição orientada por demanda, tradução nossa.

${ }^{5}$ Empréstimo de curto prazo, tradução nossa.

${ }^{6}$ Aquisição baseada em evidência, tradução nossa.
} 
decorrência de término ou rompimento de contrato de editores ou autores, ou ainda, por descontinuidade da plataforma de leitura ou eventuais restrições legais.

\section{Considerações finais}

No âmbito dos livros digitais se observa um cenário de transformações, com papéis e formas de atuação sendo experimentadas. Um dos pontos que vem representando desafios às bibliotecas é a não aderência de materiais digitais à Teoria da Primeira Venda que, ao remover a propriedade de objetos imateriais, proporciona que a aquisição seja realizada por meio de contratos de licenciamento, com a biblioteca não garantindo a propriedade das obras contratadas. Este entendimento afeta o serviço prestado pelas instituições e, pode-se inclusive, vislumbrar um risco na autonomia das bibliotecas, uma vez que elas podem encontrar restrições para realizar empréstimos.

Os fornecedores de livros digitais, aparentemente, se mostram interessados na extinção da Teoria da Primeira Venda, afinal isto representaria a aplicação de outros modelos de negócios, com o uso temporário de uma obra (modelos transitórios) em detrimento da propriedade sem data para expirar (modelo perene), resultando em ganhos recorrentes, em comparação a uma compra e pagamento realizados em transação única.

As bibliotecas já vivenciam desafios em relação à manutenção de periódicos eletrônicos e bases de dados, cuja contratação é realizada por meio de assinaturas. Este modelo não se mostra interessante, em decorrência da instabilidade de orçamentos que, em caso de não renovação de serviços, podem acarretar na remoção de registros bibliográficos das coleções. Este processo, além de representar um investimento constante para manutenção temporária dos acervos, também pode resultar em restrições de acesso aos conteúdos, com títulos sendo removidos de plataformas de fornecedores ou com a biblioteca impossibilitada de manter contratos ativos.

A Teoria da Primeira Venda não vem sendo discutida pelas bibliotecas brasileiras, provavelmente em decorrência da baixa oferta de livros digitais, e por não constar de forma expressa na legislação brasileira. É importante iniciar esta discussão entre os bibliotecários e estes com os fornecedores, visando encontrar um equilíbrio entre as partes, de forma a não prejudicar a autonomia das bibliotecas e garantir a permanência dos fornecedores no mercado do livro. Entende-se que os livros digitais são desconhecidos de todos os participantes deste mercado - fornecedores, bibliotecas e leitores -, porém as discussões devem ser iniciadas, testando modelos e adequando as orientações e avanços 
alcançados em instituições estrangeiras, fazendo os devidos ajustes à realidade brasileira.

O momento é de indefinição, com modelos e entendimentos jurídicos aguardando a acomodação do mercado, em busca de um equilíbrio entre as partes. Contudo, nota-se que as bibliotecas ficam fragilizadas sem a manutenção da Teoria da Primeira Venda, cabendo a elas um posicionamento para tentar assegurar esta condição.

\section{Referências}

ALBITZ, B.; BRENNAN, D. Licensing of e-books. In: KAPLAN, R. (Ed). Building and managing e-book collection. Chicago: Neal-Schuman, 2012. p. 75-84. (How-to-do-it manuals)

AMERICAN LIBRARY ASSOCIATION. Copyright. 2014. Disponível em: <http://www.ala.org/advocacy/copyright>. Acesso em: 6 mar. 2014.

AMERICAN LIBRARY ASSOCIATION. First sale doctrine and Kirtsaeng $v$. Wiley \& Sons, Inc. 2015. Disponível em: <http://www.ala.org/advocacy/copyright/firstsale > . Acesso em: 3 out. 2015.

ARÉVALO, J. A.; GÓMES DÍAZ, R.; CORDÓN GARCIA, J. A. E-books en bibliotecas: gestión, tratamento y aplicaciones. Buenos Aires: Alfagrama, 2015.

BRASIL. Presidência da República. Lei no 9.609, de 19 de fevereiro de 1998. Dispõe sobre a proteção da propriedade intelectual de programa de computador, sua comercialização no País, e dá outras providências. Diário Oficial [da] República Federativa do Brasil, Poder Executivo, Brasília, DF, 20 fev. 1998a. Seção 1. Disponível em: <http://www.planalto.gov.br/ccivil_03/Leis/L9609.htm>. Acesso em: 22 mar. 2014.

BRASIL. Presidência da República. Lei no 9.610, de 19 de fevereiro de 1998. Altera, atualiza e consolida a Legislação sobre Direitos Autorais. Diário Oficial [da] República Federativa do Brasil, Poder Executivo, Brasília, DF, 20 fev. 1998b. Seção 1. Disponível em: <http://www.planalto.gov.br/ccivil 03/leis/19610.htm>. Acesso em: 22 mar. 2014.

COSTA, R. P. Modelos de comercialização de livros eletrônicos para bibliotecas do Distrito Federal. 2015. 186f. Dissertação (Mestrado em Ciência da Informação) -Universidade de Brasília, 2015. Disponível em: <http://repositorio.unb.br/handle/10482/19212>. Acesso em: 14 abr. 2017.

EUROPEAN BUREAU OF LIBRARY, INFORMATION AND DOCUMENTATION ASSOCIATIONS. As bibliotecas europeias e os desafios da edição eletrônica. 2012. Disponível em: <http://www.eblida.org/Special Events/Key-principles-acquistion-eBooksNovember2012/GB_EnglishVersionKey Principles.pdf>. Acesso em: 1 nov. 2012. 
EUROPEAN BUREAU OF LIBRARY, INFORMATION AND DOCUMENTATION ASSOCIATIONS. The right to e-read: an e-book policy for libraries in Europe. 2013. Disponível em: <http://www.eblida.org/News/The\%20right\%20to\%20eread.pdf?PHPSESSID=a3215750b37cdd445fd57ed370d7e0ce >. Acesso em: 1 dez. 2013.

GEE, W. The conundrum of ebooks and interlibrary loan. Against the grain, v. 19, n. 2, 2007. Disponível em: <https://doi.org/10.7771/2380-176X.5047>. Acesso em: 10 mar. 2018.

GEIST, R. A. A "license to read": the effect of e-books on publishers, libraries, and the first sale doctrine. IDEA: The IntellFectual Property Law Review, v. 52, n. 1, 2012. Disponível em: <http://ipmall.info/hosted resources/IDEA/idea-vol52-no1geist.pdf $>$. Acesso em: 3 out. 2015.

HARTE, L. Introduction to DRM [recurso eletrônico]: identifying, tracking, authorizing and restricting access to digital media. New York: Althos, 2007.

INTERNATIONAL FEDERATION OF LIBRARIES ASSOCIATIONS (IFLA). Principles for library elending. 2013. Disponível em: $<$ http://www.ifla.org/files/assets/hq/topics/e-lending/principles-for-library-elendingrev-aug-2013.pdf >. Acesso em: 3 out. 2015.

KONNIKOVA, M. How to make a book disappear. The Atlantic, New York, 18 set. $2012 . \quad$ Disponível em: $<$ https://www.theatlantic.com/entertainment/archive/2012/09/how-tomake-a-book-disappear/262469/>. Acesso em: 10 mar. 2018.

MAIA, J. T. de M. A relação jurídica entre o distribuidor e o consumidor do livro digital. In: CONGRESSO INTERNACIONAL CBL DO LIVRO DIGITAL, 4., 2013, São Paulo. Trabalhos acadêmicos finalistas. São Paulo: CBL, $2013 . \quad$ p. 1-9. Disponível em: <http://www.congressodolivrodigital.com.br/arq-trabalhos-cientificos/TCjoana-teixeira-de-mello-maia-010513192154.pdf>. Acesso em: 9 mar. 2014.

MCGUIRE, H.; O'LEARY, B. Book [recurso eletrônico]: a futurist's manifesto: essay from the bleeding edge of publishing. Chicago: O'Reilly, 2012.

OVERDRIVE; AMERICAN LIBRARY ASSOCIATION. Library ebook survey hosted by OverDrive and American Library Association (ALA). 2012. Disponível em: <http://blogs.overdrive.com/files/2012/11/ALA ODSurvey.pdf > . Acesso em: 30 set. 2015.

POLANKA, S. The no shelf required guide to e-book purchasing [recurso eletrônico]. Library Technology Reports, Chicago, v. 47, n. 8, p. 1-59, 2011.

RAO, S. S. Electronic books: their integration into library and information centers. The electronic library, v. 23, n. 1, p. 116-140, 2005. 
ROCHA, H. R. Software \& Direito: dos contratos: licença de uso e serviços. Âmbito Jurídico, Rio Grande, v. 10, n. 42, jun. 2007. Disponível em: $<$ http://www.ambito-

juridico.com.br/site/index.php?n link=revista artigos leitura\&artigo id=1914 >.

Acesso em: 21 maio 2014.

SERRA, L. G. Os livros eletrônicos e as bibliotecas. 2015. $189 \mathrm{f}$. Dissertação (Mestrado em Cultura e Informação) - Escola de Comunicações e Artes, Universidade de São Paulo, São Paulo, 2015. Disponível em: <doi:10.11606/D.27.2015.tde-01122015-101516>. Acesso em: 14 abr. 2017.

SERRA, L. G.; SILVA, J. F. M. da. Livros digitais licenciados e os modelos de negócios transitórios. In: CONTECSI - INTERNATIONAL CONFERENCE ON INFORMATION SYSTEMS AND TECHNOLOGY MANAGEMENT, 13., 2016, São Paulo. Anais... São Paulo: Tecsi, 2016. p. 878-893. Disponível em: <DOI: 10.5748/9788599693124-13CONTECSI/PS-3786>. Acesso em: 14 abr. 2017.

SHEEHAN, K. The ebook revolution [recurso eletrônico]: a primer for librarians on the front lines. Santa Barbara, CA: ABC-CLIO, 2013.

STONE, B. Amazon erases Orwell books from Kindle. The New York Times, New York, 17 jul 2009. Disponível em: <http://www.nytimes.com/2009/07/18/technology/companies/18amazon. html>. Acesso em: 10 mar. 2018.

THE UNITED States of America. Copyright Law. Chapter 1: Subject matter and scope of copyright. 2011. Disponível em: <http://www.copyright.gov/title17/92chap1.html\#109>. Acesso em: 5 maio 2014.

WALTERS, W. H. E-books in academic libraries: challenges for acquisition and collection management. Libraries and the Academy, v. 13, n. 2, p. 187-211, 2013.

WOODS, B.; IRELAND, M. eBook loans: an e-twist on a classic interlending service. Interlending \& Document Supply, v. 36, n. 2, p. 105-115, 2008. Disponível em: $<$ http://www.emeraldinsight.com/doi/pdfplus/10.1108/02641610810878585>. Acesso em: 17 fev. 2015.

WOODWARD, J. The transformed library: e-books, expertise, and evolution. Chicago: ALA, 2013. 